\title{
Influence of Carbon Fiber Direction on EDM Characteristics of CFRP
}

\author{
Sho ICHII ${ }^{1}$, Akira OKADA ${ }^{2}$, Yasuhiro OKAMOTO ${ }^{3}$ and Yoshiyuki UNO $^{4}$ \\ ${ }^{1}$ Okayama University, 3-1-1 Tsushimanaka, Kita-ku, Okayama 700-8530, Japan, ichii@ntmlab.mech.okayama-u.ac.jp \\ ${ }^{2}$ Okayama University, okada@mech.okayama-u.ac.jp \\ ${ }^{3}$ Okayama University, okamoto@mech.okayama-u.ac.jp \\ ${ }^{4}$ Okayama University, uno@mech.okayama-u.ac.jp
}

\begin{abstract}
:
In this study, the machining characteristics and the removal mechanism in EDM for one directional CFRP was discussed in order to investigate the influence of carbon fiber direction to machining direction and to attain high performance EDM. Then EDM characteristics with two different combinations of machining direction and carbon fiber direction were compared. Experimental results clarified that the material removal mechanism in the EDM for one directional CFRP when the machining direction is perpendicular to the fiber direction is different from that in parallel machining. Therefore, efficient EDM for CFRP is possible by selecting appropriate machining direction to fiber direction.
\end{abstract}

Keywords: Electrical discharge machining (EDM), Carbon fiber reinforced plastic (CFRP), Material removal rate, Electrode wear, Surface roughness

\section{Introduction}

Carbon fiber reinforced plastic (CFRP) is distinguished by its extremely high strength, high rigidity, high resistance to impact, high corrosion resistance and light weight. The positive characteristics mean that CFRP can be used for applications in aerospace, automotive industries, and sport equipments.

Manufacturing process is one of the most important factor controlling the successful use of CFRP material. Conventional mechanical techniques such as drilling, turning, milling and etc. for machining CFRP, have many problems such as delamination, splintering, the presence of burrs and short tool life due to its high specific strength, high specific modulus, and composite structure [1][2][3][4]. Nontraditional machining methods such as laser, water jet and ultrasonic can be used to cut CFRP, but some difficulties were reported [5][6][7][8].

Electrical discharge machining (EDM) is one of the nontraditional machining processes which can be widely used to machine hard materials. Also, it is an effective alternative for generating very complicated shapes with high accuracy for advanced materials.

In our previous study [9], the fundamental EDM characteristics, such as material removal rate, electrode wear ratio and surface roughness for two directional CFRP practically applied as products have been experimentally investigated with varying discharge peak current and pulse duration, and it was made clear that the CFRP had high EDM machinability. However, the influence of carbon fiber direction to machining direction on EDM characteristic has not yet been clarified.

In this study, the influence of carbon fiber direction to machining direction on EDM characteristics, including the material removal rate, the machined surface roughness and the electrode wear were experimentally investigated using one directional CFRP as workpiece. Also the material removal mechanism in the EDM for one directional CFRP was discussed in order to attain high performance EDM .

\section{Experimental Procedures}

The experiments were carried out using $\mathrm{NC}$ die sinking EDM (Sodick AQ35LR). A kerosene type working fluid (Sodick hightech VITOL2) was used. Cylindrical copper and graphite (Ibiden ED-3) of $8 \mathrm{~mm}$ in diameter were used as an electrode. The workpiece material was CFRP sheet (Sakai Industries F63438-05) with one directional carbon fibers formed by the autoclave method. In the autoclave molding method, CFRP sheet is produced by heating and pressing some layers consist of carbon fibers and epoxy resin with high

Table 1 : Properties of CFRP.

\begin{tabular}{ll|c}
\hline Carbon fiber & & TORAY T300 \\
\hline Fiber content ratio & $(\mathrm{vol} . \%)$ & 60 \\
\hline Plastic & & Epoxy \\
\hline Elasticity & $\left(\mathrm{kgf} / \mathrm{mm}^{2}\right)$ & $23.5 \times 10^{3}$ \\
\hline Density & $(\%)$ & 1.52 \\
\hline
\end{tabular}

Table 2 : EDM conditions.

\begin{tabular}{ll|c}
\hline Discharge current & $(\mathrm{A})$ & 3 \\
\hline Open circuit voltage & $(\mathrm{V})$ & 120 \\
\hline Pulse duration & $(\mu \mathrm{s})$ & $5-200$ \\
\hline Duty factor & $(\%)$ & $33.3,20.0$ \\
\hline Working fluid & Kerosene \\
\hline Electrode material & Copper and graphite \\
\hline Workpiece material & CFRP and SKD11 \\
\hline Machining depth $\quad(\mathrm{mm})$ & 1.0 \\
\hline
\end{tabular}


ductility. Mechanical properties of the CFRP used in this study are shown in Table 1. Metal mold steel SKD11 was also machined for comparison.

EDM conditions are shown in Table 2. A series of EDM experiments with varying discharge conditions were carried out. According to Wang's study[9], the machining state becomes unstable and the removal rate decreases under large discharge current conditions in the EDM for CFRP. Therefore, small discharge current 3A was fixed and pulse duration was varied in this study. EDM characteristics such as material removal rate, electrode wear ratio, and surface roughness were evaluated when cylindrical cavity of $1.0 \mathrm{~mm}$ in depth is machined. Also, in order to investigate the influence of carbon fiber direction to machining direction, EDM characteristics with two different combinations of machining direction and carbon fiber direction were compared. Moreover, the material removal mechanism in the EDM for CFRP was discussed.

Figure 1 schematically shows the machining method. Figure 1 (a) shows perpendicular machining, in which machining direction and carbon fiber direction are perpendicular. On the other hand, Figure 1 (b) is parallel machining. There are represented with CFRP1- $\perp$ and CFRP1-//, respectively.

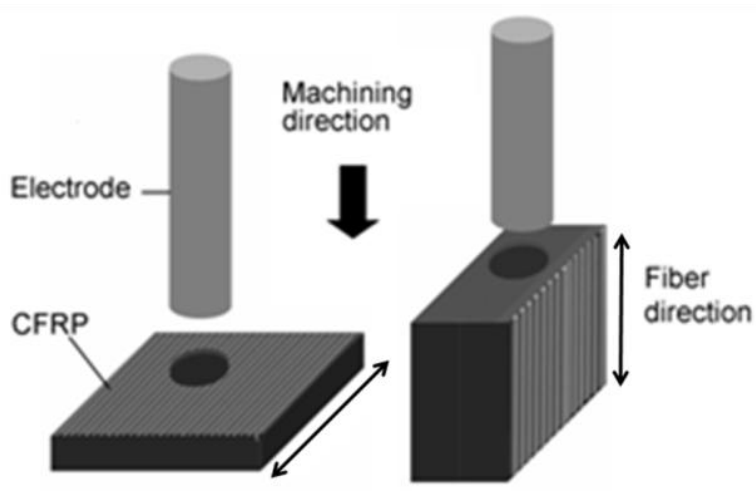

(a) CFRP1-1

(b) CFRP1- /

Figure 1 : EDM experimental set-up.

\section{Results and Discussions}

Figure 2 shows the variations of removal rate with pulse duration for $3 \mathrm{~A}$ in the discharge current. As shown in the figure, the removal rate for CFRP is much higher than that for SKD11. Therefore, it is understood that the EDM machinability of CFRP is extremely high. This is probably because the epoxy resin part in CFRP is easily melted and removed by high temperature of sparks.

Also, the variation of removal rate with pulse duration in the case of perpendicular machining is different from that in the case of parallel one. In the case of perpendicular machining, the removal rate increases with pulse duration regardless of the type of electrode. On the other hand, the removal rate is almost constant expect very short pulse durations in the case of parallel machining. In both perpendicular and parallel machining, the removal rate depends slightly on the type of a electrode. Therefore, material mechanism might depend on the machining direction to the carbon fiber direction and type of electrode.

Figure 3 shows the variations of electrode wear ratio with pulse duration. The electrode wear ratio decreases with pulse duration, and no electrode wear EDM for CFRP can be achieved in both cases of perpendicular machining and parallel one expect under the conditions of short pulse durations. There are no large difference in the electrode wear ratio with machining direction and type of electrode material.

The element analysis results of electrode surface after EDM are shown in Figure 4. As can be seen from the figure, a large amount of carbon is detected under all conditions. This reason is thought to be adhesion of heat resolved carbon not only from kerosine working fluid but also from resin in CFRP. And the heat resolved carbon protects electrodes from high temperature due to sparks. From this result, it is found that the electrode wear ratio in EDM for CFRP is smaller than that for SKD11 and no electrode wear EDM for CFRP is readily possible under appropriate conditions.

The variations of surface roughness with pulse duration are shown in Figure 5. The surface roughness

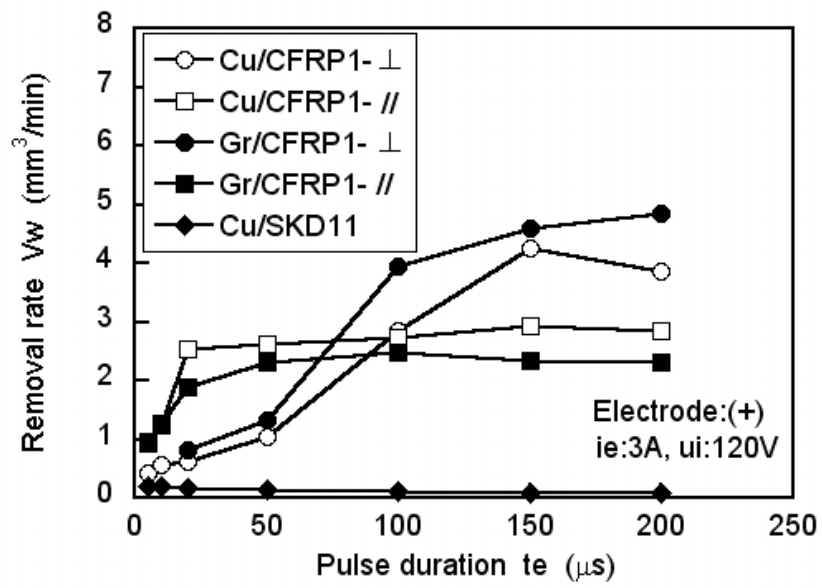

Figure 2 : Variations of removal rate for CFRP with pulse duration.

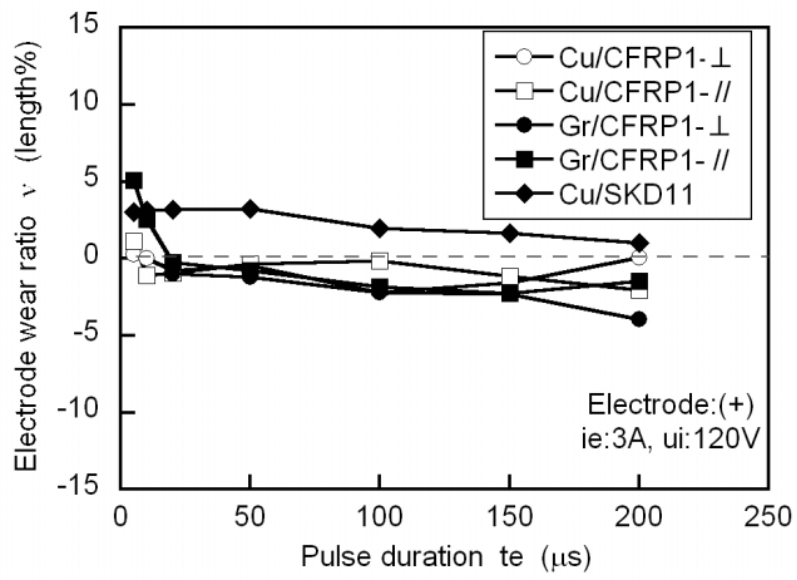

Figure 3 : Variations of electrode wear ratio with pulse duration. 
for CFRP increases with pulse duration in the case of perpendicular machining. On the other hand, the surface roughness in the case of parallel machining is smaller than that of perpendicular machining but twice larger than that for SKD11, and slightly increases with pulse duration. Furthermore, there was no large difference in surface roughness with the type of electrode material in the EDM for CFRP.

SEM images of the EDMed CFRP surface under various machining conditions using graphite electrodes are shown in Figure 6. As can be seen from the figure, in the case of parallel machining, the size of craters formed on the EDMed surface becomes larger with an increase of pulse duration. On the EDMed surfaces, both carbon fiber and resin can be observed. In the case of perpendicular machining, many carbon fibers are seen on the surface, and some of them are broken with impact of spark, but resin is hardly seen. The melting point and the boiling point of epoxy resin are very low, so it is guessed that the epoxy resin is preferentially removed, and carbon fibers remains on the surface.

Material removal mechanism in the EDM for CFRP seems to be different with the machining direction and to carbon fiber direction. In the case of parallel machining, CFRP is removed mainly by melting and boiling with high temperature of sparks. On the other hand, in the case of perpendicular one, the material is removed not only by melting and boiling with the high temperature sparks, but also by fiber breakage with the impact of spark occurrence. As a result, the removal rate in the case of perpendicular machining is larger than that in the case of parallel one.

In the EDM experiments shown above, the machining states were unstable under short pulse durations. This reason is thought to be a lack of pulse interval time. Then, the parallel machining experiments were carried out with decreasing duty factor from $33.3 \%$ to $20 \%$ using copper electrode. Figures 7 and 8 show the comparison of EDM characteristics between $20.0 \%$ and $33.3 \%$ in duty factor. As can be seen from these figures, the unstable machining can be improved even under shorter pulse durations. The surface roughness of about $5 \mu \mathrm{mRz}$ can be obtained under the pulse duration $5 \mu \mathrm{s}$.

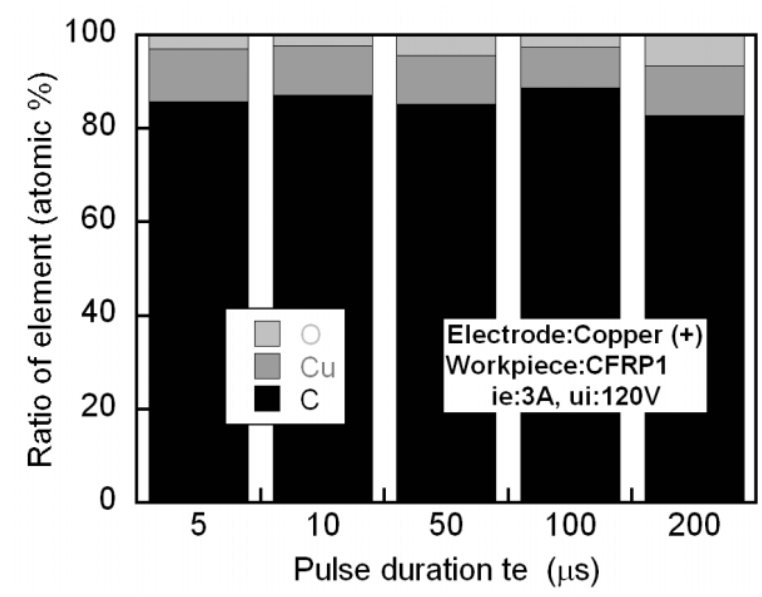

Figure 4 : Component analysis of electrode surface after EDM.

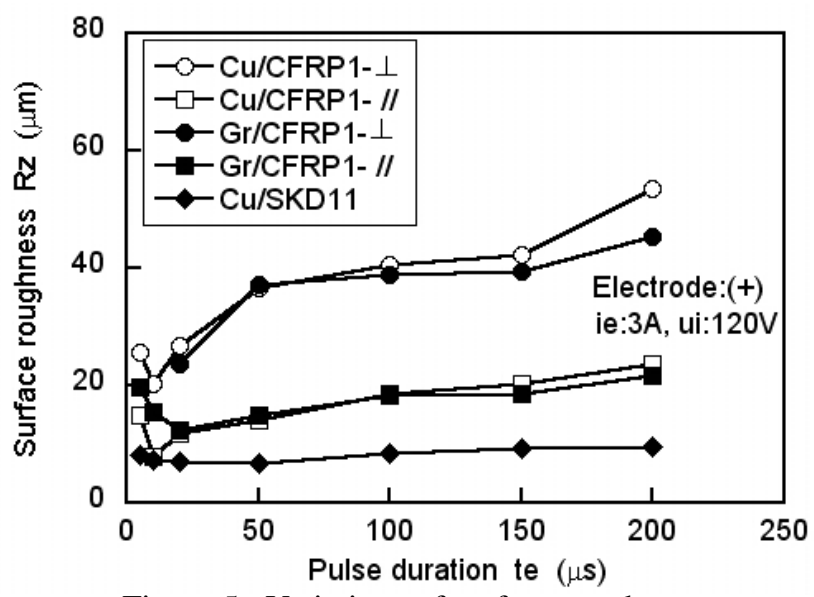

Figure 5 : Variations of surface roughness with pulse duration.

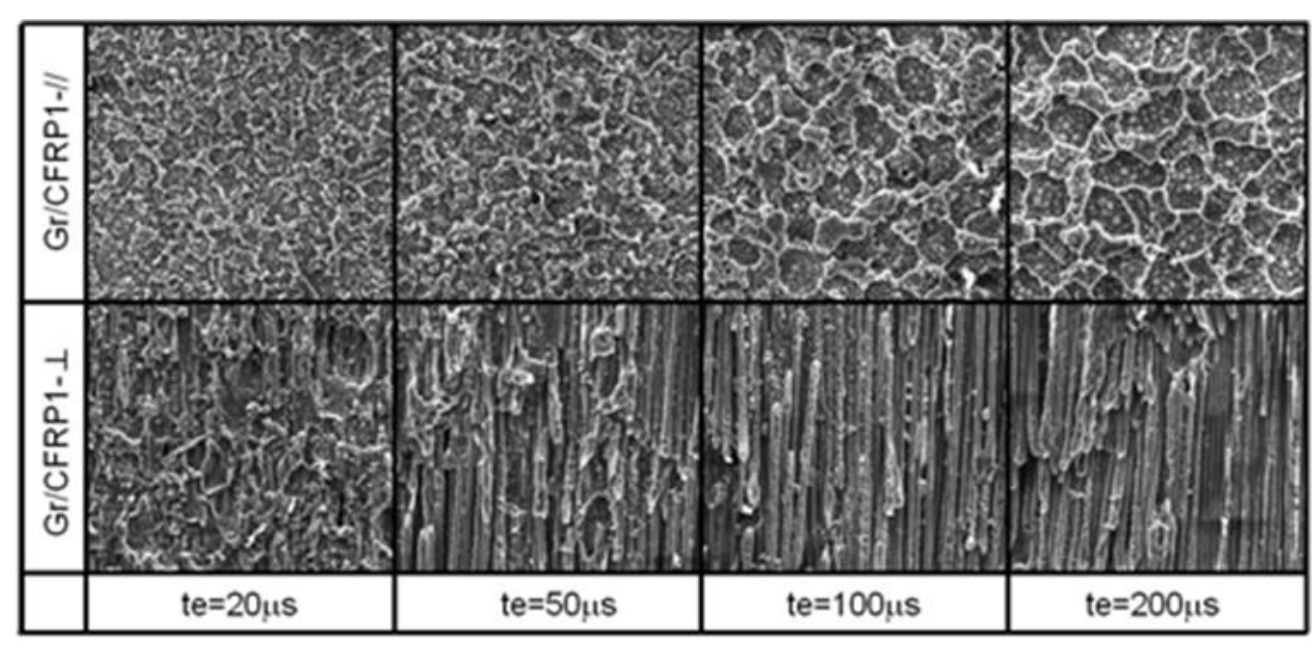

$\overline{50 \mu m}$

Figure 6 : SEM images of EDMed surface with graphite electrode. 


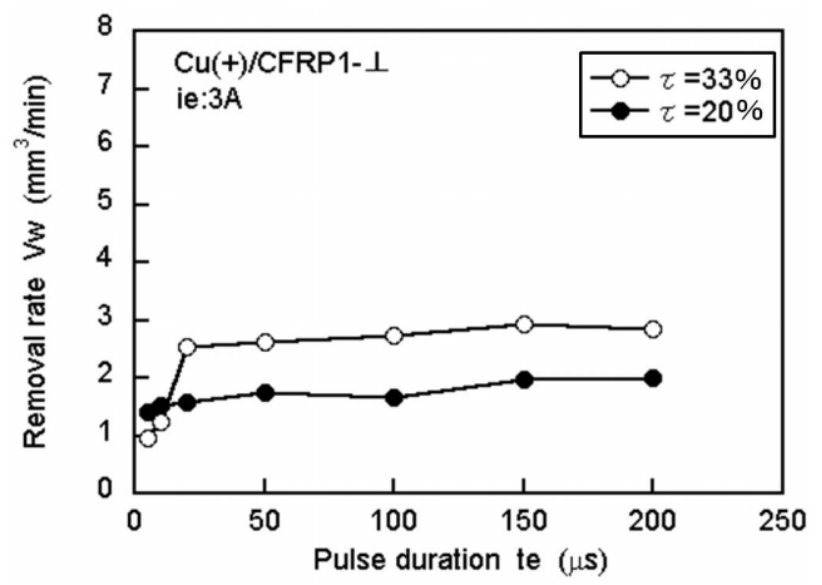

Figure 7 : Variations of removal rate with pulse duration at $\tau=33.3 \%$ and $20 \%$.

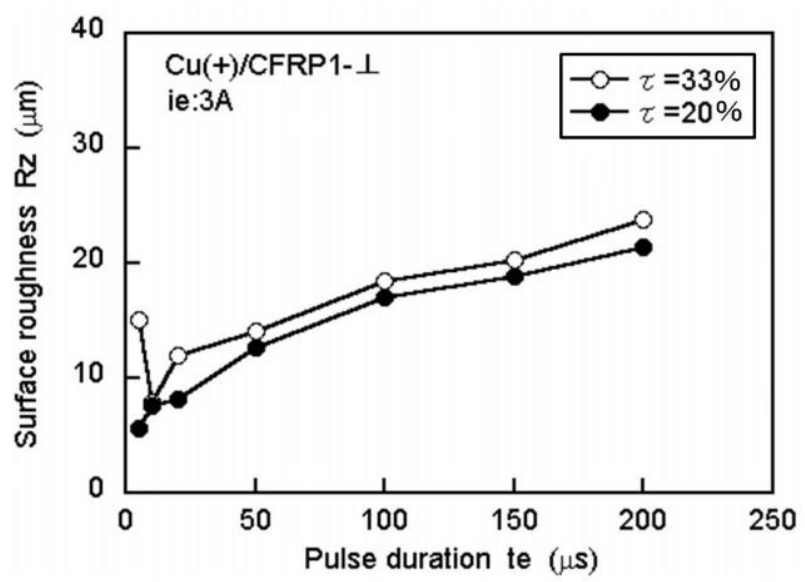

Figure 8 : Variations of surface roughness with pulse duration at $\tau=33.3 \%$ and $20 \%$.

4. Conclusions

(1) The EDM machinability of one directional CFRP is very high because of its large removal rate, compared with SKD11.

(2) The removal rate increases with pulse duration when the machining direction is perpendicular to the fiber direction.

(3) The removal rate is almost constant regardless of pulse duration when the machining direction is parallel to the fiber direction.

(4) Electrode wear ratio in the EDM for one directional CFRP becomes very small by much adhesion of heat resolved carbon from kerosine working fluid and resin in CFRP.

(5) There are no large differences in the EDM characteristics for one directional CFRP with the type of electrode material

(6) Material removal mechanism in the EDM for one directional CFRP when the machining direction is perpendicular to the fiber direction is different from that in parallel machining.

\section{References}

[1] Lau, W.S., Wang, M. and Lee, W.B., 1990, Electrical Discharge Machining of Carbon Fiber Composite Materials, International Journal of Machining Tools and Manufacturing, Vol.30, No.2, pp.297-308.

[2] Hocheng, H. and Tsao, C.C., 2005, The Path towards Delamination-free Drilling of Composite Materials, Journal of Materials Processing Technology, No.167, pp.251-264.

[3] Koplev, A., Lystrup, A. and Vorm, T., 1983, The Cutting Process Chips and Cutting Forces in Machining CFRP, Composites, Vol.14, No.2, pp.371-376.

[4] Chen, W.C. 1997, Some Experimental Investigations in the Drilling of Carbon Fiber Reinforced Plastic (CFRP) Composite Laminates, International Journal of Machining Tools and Manufacturing, Vol.37, No.8, pp.1097-1108.

[5] Caprino, G. and Tagliaferri, V., 1988, Maximum Cutting Speed in Laser Cutting of Fiber Reinforced Plastics, International Journal of Machining Tools and Manufacturing, Vol.28, No.4 , pp. 389-398.

[6] Muller, F. and Monagham, J., 2000, Non-conventional Machining of Particle Reinforced Metal matrix Composite, International Journal of Machining Tools and Manufacturing, Vol.40, pp.1351-1366.

[7] Cheng, H. H., 1990, A Failure Analysis of Water Jet Drilling in Composite Laminates, International Journal of Machining Tools and Manufacturing, Vol.30, No. 3, pp.423-429.

[8] Tandon, S., Jain, V. K., Kumar, P. and Rajurkar, K. P., 1990, Investigations into Machining of Composities, Precision Engineering, Vol.12 No.4, pp.227-238.

[9] Wang, H., Habib, S., Okada, A. and Uno, Y., 2010, EDM Characteristics of Carbon Fiber Reinforced Plastic, Proc. of the 16th International Symposium on ElectroMachining, pp.65-68. 